\title{
Steroid Withdrawal Based on Lymphocyte Sensitivity to Endogenous Steroid in Renal Transplant Recipients
}

\author{
Hironori Takeuchi, ${ }^{*, a}$ Naoto Matsuno, ${ }^{b}$ Toshihiko Hirano, ${ }^{c}$ Muhetaer Gulimire, ${ }^{d}$ Koichiro Hama, ${ }^{d}$ \\ Yuki Nakamura, ${ }^{d}$ Hitoshi Imamoto, ${ }^{d}$ Tatsunori Toraishi, ${ }^{e}$ Takashi Kawaguchi, ${ }^{a}$ Kiyoshi Okuyama, ${ }^{e}$ \\ Sakae UnEZAKI, ${ }^{a}$ and Takeshi NAGAO ${ }^{d, \dagger}$ \\ ${ }^{a}$ Department of Practical Pharmacy, Tokyo University of Pharmacy and Life Sciences; ${ }^{c}$ Department of Clinical \\ Pharmacology, Tokyo University of Pharmacy and Life Sciences; 1432-1 Horinouchi, Hachioji, Tokyo 192-0392, Japan: \\ ${ }^{b}$ Department of Surgery, Center for Liver Disease, Higashi Totsuka Memorial Hospital; 548-7 Shinano, Totsuka, \\ Kanagawa 244-0801, Japan: ${ }^{d}$ The Fifth Department of Surgery, Hachioji Medical Center, Tokyo Medical University; and \\ ${ }^{e}$ Department of Pharmaceutics, Hachioji Medical Center, Tokyo Medical University; 1163 Tatemachi, Hachioji, Tokyo \\ 193-0998, Japan. Received April 15, 2011; accepted July 25, 2011; published online July 27, 2011
}

\begin{abstract}
Though steroid withdrawal is done in many renal transplant recipients, some patients must restart steroids. Little report has investigated steroid withdrawal under pharmacodynamic monitoring. We assessed lymphocyte sensitivity to endogenous cortisol as a biomarker for determining the safety of steroid withdrawal in renal transplant patients, as we hypothesized that patients hyposensitive to cortisol could not be sufficiently immunosuppressed by their intrinsic cortisol as a substitute for the reduced or withdrawn steroid. Lymphocyte sensitivity to cortisol was examined in 30 long stable renal transplant recipients. Lymphocyte sensitivity to cortisol and its relationship with the clinical outcome after steroid reduction and withdrawal was investigated. The lymphocyte sensitivities to cortisol were estimated as $\mathrm{IC}_{50}$ of lymphocyte blastogenesis. The lymphocyte proliferation rate for concentration of serum cortisol compared between incident and non-incident groups. Serum creatinine levels (S$\mathrm{Cr}$ ) increased in a significantly higher number of patients hyposensitive to cortisol $\left(\mathrm{IC}_{50} \geqq 10000 \mathrm{ng} / \mathrm{ml}\right)$ than in normally sensitive patients $\left(\mathrm{IC}_{50}<10000 \mathrm{ng} / \mathrm{ml}\right)$. The incidences of steroid withdrawal syndrome and necessity for increasing steroid dose or restarting steroid administration were also higher in the patients hyposensitive to cortisol. The patients in whom the lymphocyte proliferation rate was less than $60 \%$ did not show increase in $\mathrm{S}-\mathrm{Cr}$, experience steroid withdrawal symptoms, or require an increase in the steroid dose or restart of steroid administration. The patients who have the normal $\mathrm{IC}_{50}$ values of cortisol, can withdraw steroid more safely. The lymphocyte sensitivity to cortisol may be a useful biomarker for selecting patients who can sustain steroid withdrawal.
\end{abstract}

Key words steroid withdrawal; lymphocyte sensitivity; endogenous cortisol; renal transplant recipient; biomarker

Although acute rejection episodes in the early phase of renal transplants have considerably decreased since the development of basiliximab, ${ }^{1,2}$ the adverse events associated with the long-term use of immunosuppressive drugs still exist. ${ }^{3,4)}$ Decreasing these adverse events is a major goal in the treatment of transplant recipients. It is believed that the steroids in maintenance immunosuppressive drugs produce severe adverse events most associated with morbidity, such as cardiovascular disease,${ }^{3)}$ and therefore, the use of steroids is withdrawn for many renal transplant recipients. ${ }^{5)}$ However, steroids need to be restarted to prevent the worsening of renal function because of acute rejection episodes in some patients $^{6-9)}$ or in patients who experience steroid withdrawal syndrome. Currently, there are no indicators to predict which patients can sustain steroid withdrawal.

In our previous report, we found that lymphocyte sensitivity to steroids in vitro evaluated before transplantation is closely related to the clinical efficacy of the drugs. ${ }^{10,11)}$ Then, we focused on the lymphocyte sensitivity to endogenous cortisol after steroid reduction as a biomarker for determining the safety of steroid withdrawal. As patients hyposensitive to cortisol are suggested not to be sufficiently immunosuppressed by their intrinsic cortisol as a immunosuppressive substitute for the reduced or withdrawn steroid, we hypothesized in the present study that cortisol hyposensitive patients

\footnotetext{
${ }^{\dagger}$ Present address: Department of Surgery, Jinwakai Hospital; 4-8-1

Myoujinchou, Hachioji, Tokyo 192-0046, Japan.

will not be withdrawn steroid safely. For this, we measured the lymphocyte sensitivity to cortisol, administered steroids, and calcineurin inhibitors (CNIs) in long-term stable renal transplant patients, and retrospectively investigated the relationship between this lymphocyte sensitivity and the clinical outcome after steroid reduction and ultimately, withdrawal.

\section{MATERIALS AND METHODS}

Subjects This study was approved by the Ethical Committee of Hachioji Medical Center, Tokyo Medical University, and informed consent was obtained from all patients. This study was performed from July 2008 to December 2009. Lymphocyte sensitivity to cortisol, administered steroids, and CNI was examined in 30 renal transplant recipients aged median of 49.5 years (interquartile range, 37.75 to 63.5) (14 males and 16 females). The mean body weight of the patients was median of $55.0 \mathrm{~kg}$ (interquartile range, 44.0 to 64.0). Of these, 22 patients had received renal grafts from living related donors, and 8 , from a cadaver donor; 28 patients had received transplants from $\mathrm{ABO}-$-compatible donors, and 2, from ABO-incompatible donors; and 26 patients had received their first allograft transplant and 4, the second one. Fifteen patients experienced acute rejection episodes, and 15 patients experienced cytomegalovirus (CMV) infection episodes. Some patients had received drugs such as gastropyloric drugs, antihypertensive drugs, antihyperlipidemic drugs, and antihyperuricemic drugs. Lymphocyte sensitivity 
was measured after a median of 6.6 years (interquartile range, 2.4 to 13.0 ) from the renal transplant, and a median of 1.3 years (interquartile range, 0.2 to 2.2 ) years after final reduction of steroid or withdrawal. The patient profiles are shown in Table 1.

Immunosuppressive Therapy Imuunosuppressive induction therapy and maintenance immunosuppressive therapy were carried out based on steroid, CNI, and antimetabolic drugs as shown in Table 1.

At the time of measuring lymphocyte sensitivity, steroids were being administered to 24 patients and had been discontinued for 6 patients. The steroids were methylprednisolone (given to 25 patients) and prednisolone (given to 5 patients). When converted to methylprednisolone equivalents, the doses given to patients in whom steroids were being reduced were less than $6 \mathrm{mg} / \mathrm{d}$, and the mean dose of steroids was median of $2.0 \mathrm{mg} / \mathrm{d}$ (interquartile range, 0.75 to 2.5 ). The CNIs administered were cyclosporine (CYA) given to 20 patients and tacrolimus (TAC) given to 10 patients. The mean blood trough concentration of CYA was median of $33.5 \mathrm{ng} / \mathrm{ml}$ (interquartile range, 22 to 59.8). and that of TAC was median of $5.2 \mathrm{ng} / \mathrm{ml}$ (interquartile range, 3.6 to 5.9). The antimetabolite drugs mycophenolate mofetil, azathioprine, mizoribine, and a non-antimetabolite drug were given to $15,9,5$, and 1 patients, respectively. No patients were administered rituximab.

Lymphocyte Sensitivity to Steroids and CNIs ${ }^{10,11)} \mathrm{Ve}-$ nous blood was taken from each patient at 8:00 a.m. before taking the immunosuppressive drugs and heparinized. The heparinized blood $(10 \mathrm{ml})$ was layered on $3 \mathrm{ml}$ of Ficoll-Hypaque solution and centrifuged at $1300 \times \boldsymbol{g}$ for $15 \mathrm{~min}$, and the peripheral blood mononuclear cells (PBMCs), including the lymphocytes, were separated. The cells were washed and resuspended in RPMI 1640 medium, containing 10\% fetal calf serum, $100000 \mathrm{IU} / 1$ penicillin $\mathrm{G}$, and $100 \mathrm{mg} / 1$ streptomycin, to a final density of $1 \times 10^{6}$ cells $/ 1$.

The prepared cell suspension $(200 \mu \mathrm{l})$ was placed in 96 flat-bottom wells of a microtiter plate. Concanavalin A was added to each well as the mitogen, to achieve a final concentration of $5.0 \mu \mathrm{g} / \mathrm{ml}$. Subsequently, $4 \mu \mathrm{l}$ of an ethanol solution containing cortisol, methylprednisolone, or CNIs was added to the wells to give a final concentration of $0.01,0.1$, $1,10,100,1000,10000 \mu \mathrm{g} / 1$; to the control well, $4 \mu \mathrm{l}$ of ethanol was added. The plate was incubated for $96 \mathrm{~h}$ at $37^{\circ} \mathrm{C}$ in a humidified chamber containing $5 \% \mathrm{CO}_{2} /$ air. The cells were pulsed with $18.5 \mathrm{kBq} /$ well of $\left[{ }^{3} \mathrm{H}\right]$ thymidine for the last $16 \mathrm{~h}$ of incubation, collected on a glass-fiber filter paper by using a multiharvester, and dried. The radioactivity on the filter paper was further processed for liquid scintillation counting. We determined the mean of the triplicate counts obtained for each sample. The concentration of the agent that could inhibit $50 \%$ of lymphocyte mitosis $\left(\mathrm{IC}_{50}\right)$ was determined from the concentration-response curve.

As we have little data on lymphocyte sensitivities to immunosuppressive drugs in patients exposed to immunosuppressive drugs after renal transplantation, we have measured lymphocyte sensitivities to steroids (methylprednisolone) before and after renal transplantation at 3 year intervals in 2 patients with stable allograft function after renal transplantation (data not shown). In these recipients, lymphocyte sensitivities $\left(\mathrm{IC}_{50}\right.$ values) to methylprednisolone did not change, nevertheless calcineurin inhibitor, steroid, and antimetabolites have been administered.

Measurements of Serum Cortisol and Blood CNI Concentration For measuring serum cortisol concentration and blood CNI concentration, venous blood $(3 \mathrm{ml})$ was collected at 8:00 a.m. before oral administration of the medicines. Steroids were administered once a day in the morning, and the serum cortisol concentration was measured by radioimmunoassay. CNIs were given in equally divided doses of either CYA or TAC twice daily, 30 min after meals. The CYA concentrations were measured by fluorescence polarization immunoassay, and the TAC concentrations were measured by

Table 1. Comparison of Patient Profiles and Immunosuppressive Therapy between Patients Normally Sensitive (NS) and Hyposensitive (HS) to Cortisol

\begin{tabular}{|c|c|c|c|}
\hline & \multicolumn{2}{|c|}{ Lymphocyte sensitivity to cortisol $\left(\mathrm{IC}_{50}\right)$} & \multirow{2}{*}{$p$-value } \\
\hline & $\begin{array}{l}\text { NS group }(<10000) \\
\quad(n=19)\end{array}$ & $\begin{array}{l}\text { HS group }(\geqq 10000) \\
\quad(n=11)\end{array}$ & \\
\hline Gender (male/female) & $9 / 10$ & $5 / 6$ & $>0.999$ \\
\hline Age $(\text { year })^{a)}$ & $57(38,65)$ & $47(37,59)$ & 0.518 \\
\hline Body weight $(\mathrm{kg})^{a)}$ & $56(46,64)$ & $51.5(44,70)$ & 0.763 \\
\hline HLA mismatches (A, B, DR $\left.)^{a}\right)$ & $3(2,3)$ & $3(2,3.5)$ & 0.857 \\
\hline Donor (living/cadaver) & $14 / 5$ & $8 / 3$ & $>0.999$ \\
\hline Transplantation history (primary/secondary) & $17 / 2$ & $9 / 2$ & 0.611 \\
\hline ABO blood type (compatibility/incompatibility) & $17 / 2$ & $11 / 0$ & 0.519 \\
\hline Period after transplant operation (years) ${ }^{a}$ & $5.0(1.9,12.6)$ & $7.6(2.8,15.0)$ & 0.425 \\
\hline Acute rejection episode (with/without) & $8 / 3$ & $7 / 12$ & 0.128 \\
\hline CMV infection episode (with/without) & $6 / 5$ & $9 / 10$ & $>0.999$ \\
\hline \multicolumn{4}{|l|}{ Immunosuppressive therapy } \\
\hline Status of steroid therapy (reduction/withdrawal) & $15 / 4$ & $8 / 3$ & $>0.999$ \\
\hline Steroid administered (MPSL/PSL) & $14 / 5$ & $11 / 0$ & 0.128 \\
\hline Dose of steroid (mg, converted to MPSL) $)^{a)}$ & $2(1,2)$ & $2(0,4)$ & 0.567 \\
\hline Serum cortisol concentration $(\mathrm{ng} / \mathrm{ml})^{a)}$ & $113(78,140)$ & $133(108,142)$ & 0.345 \\
\hline CNI administered (CYA/TAC) & $11 / 7$ & $8 / 3$ & 0.694 \\
\hline Blood trough concentration of $\left.\mathrm{CNI}(\mathrm{CYA} / \mathrm{TAC} ; \mathrm{ng} / \mathrm{ml})^{a}\right)$ & $37.0(22.0,81.3) / 5.8(3.7,6.0)$ & $32.0(22.5,42.3) / 5.1(3.2,5.2)$ & $0.545 / 0.425$ \\
\hline Antimetabolite drug (MMF/AZ/MZ/non) & $8 / 8 / 3 / 0$ & $7 / 1 / 2 / 1$ & 0.177 \\
\hline Use of basiliximab (with/without) in induction therapy & $4 / 7$ & $8 / 11$ & $>0.999$ \\
\hline
\end{tabular}

MPSL, methylprednisolone; PSL, prednisolone; CYA, cyclosporine; TAC, tacrolimus; CNI, calcineurin inhibitor; MMF, mycophenolate mofetil; AZ, azathioprine; MZ, mizoribine. a) Median (interquartile range). 
enzyme immunoassay.

Analysis of the Relationship between Lymphocyte Sensitivity and Clinical Outcome after Steroid Reduction and Withdrawal Patients were divided into the normally sensitive and hyposensitive groups on the basis of the respective $\mathrm{IC}_{50}$ values of cortisol, steroids, and CNIs, and the clinical outcome after steroid reduction and withdrawal was retrospectively compared between these groups. The clinical outcome after steroid reduction and withdrawal was evaluated by determining the number of patients in whom serum creatinine ( $\mathrm{S}-\mathrm{Cr}$ ) increased, the number who experienced steroid withdrawal syndrome, and the number for whom the steroid dose was increased or steroid administration was restarted after steroid reduction and withdrawal. We implied that the patient in whom S-Cr increased to level more than $0.2 \mathrm{mg} / \mathrm{dl}$ under $\mathrm{S}-\mathrm{Cr}$ monitoring at least 2 times per a month before and after steroid reduction and withdrawal had reduced renal function. Steroid withdrawal syndrome was evaluated on the basis of episodes of arthralgia, myalgia, fervescence, anorexia, nausea, sleepiness, headache, and stagger.

Concentration-Lymphocyte Proliferation Rate Curve Based on Pharmacokinetic/Pharmacodynamic Analysis The relationship between the cortisol concentration-lymphocyte proliferation rate curve and serum cortisol concentration was analyzed for all patients. We calculated the lymphocyte proliferation rates for serum cortisol concentration of each patient, and compared this rate between the incident and nonincident groups. Additionally, cortisol concentration-lymphocyte proliferation rate curve was compared between patients normally sensitive and hyposensitive to cortisol within the normal range of cortisol concentration.

Statistical Analysis We used Fisher's exact probability test to compare normal and hyposensitive patients. The Wilcoxon signed rank test was used to compare the lymphocyte proliferation rates between the incident and non-incident groups. These analyses were performed using Statview. In each case, $p<0.05$ was considered to be significant.

\section{RESULTS}

Normal Range of Lymphocyte Sensitivity to Steroids and CNIs The $\mathrm{IC}_{50}$ values (median (range)) for the immunosuppressive drugs examined in the recipients were as follows: cortisol, $1470 \mathrm{ng} / \mathrm{ml}(2-10000 \mathrm{ng} / \mathrm{ml}) \quad(n=30)$; methylprednisolone, $28.1 \mathrm{ng} / \mathrm{ml}(0.74-1442.7 \mathrm{ng} / \mathrm{ml}) \quad(n=$ $25)$; prednisolone, $199.6 \mathrm{ng} / \mathrm{ml}(36.1-6485.7 \mathrm{ng} / \mathrm{ml})(n=5)$; CYA, $10.1 \mathrm{ng} / \mathrm{ml}(0.1-36.2 \mathrm{ng} / \mathrm{ml})(n=20)$; and TAC, 0.10 $\mathrm{ng} / \mathrm{ml}(0.02-0.42 \mathrm{ng} / \mathrm{ml})(n=10)$. The cutoff points for methylprednisolone, prednisolone, CYA, and TAC were defined as the average plus 2 standard deviations (S.D.) of the respective $\log \mathrm{IC}_{50}$ values estimated in healthy subjects. ${ }^{10)}$ Except for cortisol $\mathrm{IC}_{50}$ values, all laboratory test $\mathrm{IC}_{50}$ values, obtained using conventional methods, showed logarithmic normal distribution. Patients in whom the $\mathrm{IC}_{50}$ was less than the cutoff point were classified into the normally sensitive group, and those in whom $\mathrm{IC}_{50}$ was more than the cutoff point were classified into the hyposensitive group. The cutoff points of $\mathrm{IC}_{50}$ were $120 \mathrm{ng} / \mathrm{ml}$ for methylprednisolone, 446 $\mathrm{ng} / \mathrm{ml}$ for prednisolone, $58.5 \mathrm{ng} / \mathrm{ml}$ for CYA, and $0.85 \mathrm{ng} / \mathrm{ml}$ for TAC, respectively. The cutoff point of cortisol $\mathrm{IC}_{50}$ was fixed at $10000 \mathrm{ng} / \mathrm{ml}$, which can clearly separate patients into the hyposensitive and normally sensitive groups as shown in Fig. 1. In this report, we used "incident group" to refer to patients in whom the S-Cr levels increased, who experienced steroid withdrawal syndrome, or for whom the steroid dose was increased or steroid administration restarted and "nonincident group" to refer to patients who did not fall into either of these categories.

Relationship between IC $_{50}$ Values of Cortisol and Clinical Outcome after Steroid Reduction and Withdrawal The patient profiles, immunosuppressive therapy, serum cortisol concentration, blood CNI concentration, immunological factors shown in Table 1, and other administered drugs were not significantly different between patients normally sensitive $(n=19)$ and hyposensitive to cortisol $(n=11)$. The relationship between lymphocyte sensitivity to cortisol and the clinical outcome is shown in Table 2. S-Cr levels did not increase in patients normally sensitive to cortisol $(n=19)$; however, they increased in a significant number of patients hyposensitive to cortisol (5 of 11 patients) $(p<0.005)$. Steroid withdrawal syndrome was observed in a significantly higher number of patients hyposensitive to cortisol (4 of 11 patients) than in those normally sensitive to cortisol (1 of 19 patients) $(p<0.05)$. Correspondingly, the steroid dose was increased

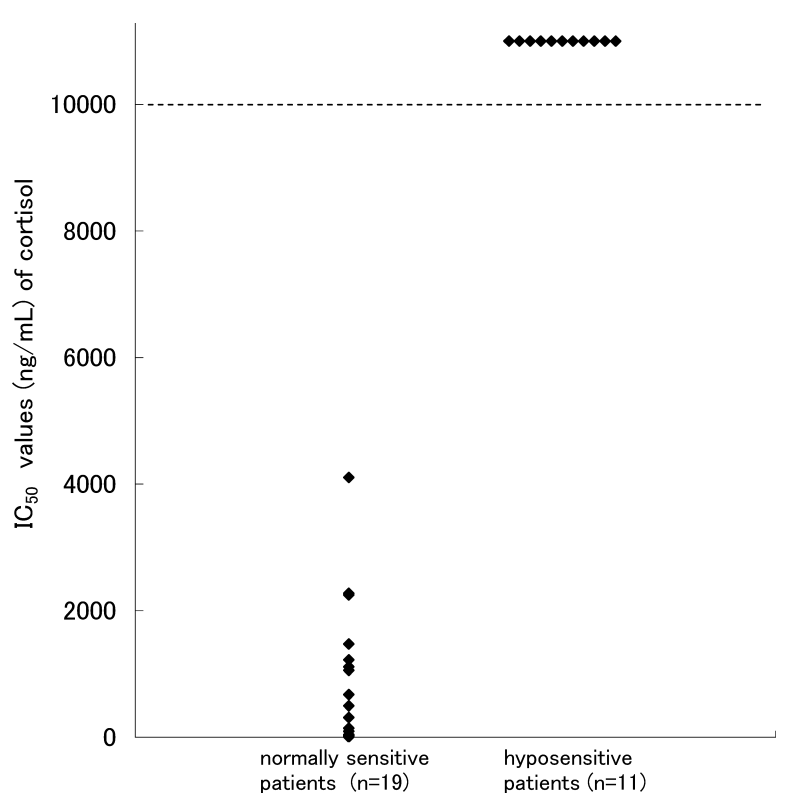

Fig. 1. Distribution of the $\mathrm{IC}_{50}$ Values $(\mathrm{ng} / \mathrm{ml})$ for Cortisol in 30 Renal Transplant Patients

Table 2. Comparison of the Incidence of Events after Steroid Reduction and Withdrawal between Patients Normally Sensitive (NS) and Hyposensitive (HS) to Cortisol

\begin{tabular}{cccc}
\hline \hline \multirow{2}{*}{$\begin{array}{c}\text { Lymphocyte sensitivity } \\
\text { to cortisol } \\
\left(\mathrm{IC}_{50}, \mathrm{ng} / \mathrm{ml}\right)\end{array}$} & $\begin{array}{c}\text { No. of patients in whom the event occurred } \\
\text { S-Cr level }\end{array}$ & $\begin{array}{c}\text { Steroid } \\
\text { withdrawal } \\
\text { syndrome }\end{array}$ & $\begin{array}{c}\text { Increase in } \\
\text { dose/restart } \\
\text { of therapy }\end{array}$ \\
\cline { 2 - 4 } & 0 & 1 & 1 \\
\hline $\begin{array}{l}\text { NS group }(<10000) n=19 \\
\text { HS group }(\geqq 10000)\end{array} n=11$ & 5 & 4 & 7 \\
\hline
\end{tabular}

Fisher's exact probability test. 
Table 3. Cases in Which Steroid Reduction and Withdrawal Did Not Succeed

\begin{tabular}{|c|c|c|c|c|c|c|c|c|}
\hline \multirow[b]{2}{*}{$\begin{array}{l}\text { Case } \\
\text { No. }\end{array}$} & \multicolumn{3}{|c|}{$\mathrm{IC}_{50}(\mathrm{ng} / \mathrm{ml})$} & \multirow{2}{*}{$\begin{array}{c}\text { Serum } \\
\text { cortisol } \\
\text { concentration } \\
(\mathrm{ng} / \mathrm{ml})\end{array}$} & \multirow{2}{*}{$\begin{array}{l}\text { Blood trough } \\
\text { concentration } \\
\text { of CNI } \\
(\mathrm{ng} / \mathrm{ml})\end{array}$} & \multirow{2}{*}{$\begin{array}{l}\text { Change in S-Cr level } \\
\text { after steroid } \\
\text { reduction/withdrawal } \\
(\mathrm{mg} / \mathrm{dl}) \\
\text { (change in dose) } \\
\text { duration of increase }\end{array}$} & \multirow{2}{*}{$\begin{array}{c}\text { Change in S-Cr level } \\
\text { after increase in the } \\
\text { steroid dose/restart } \\
\text { of therapy } \\
\text { (mg/dl) } \\
\text { (change in dose) }\end{array}$} & \multirow{2}{*}{$\begin{array}{l}\text { Symptoms } \\
\text { of steroid } \\
\text { withdrawal } \\
\text { syndrome }\end{array}$} \\
\hline & Cortisol & $\begin{array}{c}\text { Steroid } \\
\text { administered } \\
\text { (MPSL } \\
\text { for all) }\end{array}$ & $\begin{array}{l}\mathrm{CNI} \\
\text { administered }\end{array}$ & & & & & \\
\hline 1 & $\geqq 10000$ & $\geqq 1000$ & 33.3 (CYA) & 66 & 66 & - & - & $\begin{array}{c}\text { Arthralgia } \\
\text { (systemic, finger) }\end{array}$ \\
\hline 2 & 140 & 50 & 0.06 (TAC) & 83 & 5.8 & - & - & Arthralgia (finger) \\
\hline 3 & $\geqq 10000$ & 22 & 24.0 (CYA) & 137 & 32 & $\begin{array}{c}0.8 \rightarrow 1.2 \\
(2 / 0 \mathrm{mg} \rightarrow 0 \mathrm{mg}) 2 \text { months }\end{array}$ & $\begin{array}{c}1.2 \rightarrow 0.9 \\
(0 \mathrm{mg} \rightarrow 2 \mathrm{mg})\end{array}$ & Arthralgia (shoulder) \\
\hline 4 & $\geqq 10000$ & $\geqq 1000$ & 26.2 (CYA) & 87 & 45 & $\begin{array}{c}1.4 \rightarrow 1.7 \\
(4 \mathrm{mg} \rightarrow 2 \mathrm{mg}) 4 \text { months }\end{array}$ & $\begin{array}{c}1.7 \rightarrow 1.4 \\
(2 \mathrm{mg} \rightarrow 4 \mathrm{mg})\end{array}$ & - \\
\hline 5 & $\geqq 10000$ & $\geqq 1000$ & 0.03 (TAC) & 127 & 3.2 & $\begin{array}{c}2.9 \rightarrow 3.7 \\
(4 \mathrm{mg} \rightarrow 2 \mathrm{mg}) 4 \text { months }\end{array}$ & $\begin{aligned} 3.7 & \rightarrow 2.4 \\
(2 \mathrm{mg} & \rightarrow 4 \mathrm{mg})\end{aligned}$ & - \\
\hline 6 & $\geqq 10000$ & $\geqq 1000$ & 23.5 (CYA) & 161 & $<20$ & $\begin{array}{c}1.1 \rightarrow 1.4 \\
(2 / 0 \mathrm{mg} \rightarrow 0 \mathrm{mg}) 4 \text { months }\end{array}$ & $\begin{aligned} 1.4 & \rightarrow 1.8 \\
(0 \mathrm{mg} & \rightarrow 2 \mathrm{mg})\end{aligned}$ & Arthralgia (backache) \\
\hline 7 & $\geqq 10000$ & 69 & 0.98 (CYA) & 142 & 34 & $\begin{array}{c}1.3 \rightarrow 1.5 \\
(4 / 2 \mathrm{mg} \rightarrow 2 \mathrm{mg}) 4 \text { months }\end{array}$ & $\begin{array}{c}1.5 \rightarrow 1.3 \\
(2 \mathrm{mg} \rightarrow 4 \mathrm{mg})\end{array}$ & - \\
\hline 8 & $\geqq 10000$ & 69 & 8.34 (CYA) & 133 & 32 & - & - & Arthralgia (backache) \\
\hline
\end{tabular}

For the definition of abbreviations, refer to the footnotes of Table 1

or steroids were restarted in a significantly higher number of patients in the hyposensitive group ( 7 of 11 patients) than in the normally sensitive group ( 1 of 19 patients) $(p<0.005)$. The serum cortisol concentration recovered to within the normal range in all but 1 patient. There was no significant relationship between serum cortisol concentration and the clinical outcome after steroid reduction and withdrawal.

Reduction and withdrawal of steroids was unsuccessful in 8 patients because of an increase in the S-Cr level or the occurrence of withdrawal syndrome (Table 3). Except for case 2 , these patients belonged to the cortisol-hyposensitive group $\left(\mathrm{IC}_{50} \geq 10000 \mathrm{ng} / \mathrm{ml}\right)$. Only case 5 of the patients in which steroid reduction and withdrawal did not succeed was a secondary transplant recipient and there were no $\mathrm{ABO}$ incompatible transplant patients among them.

The duration of increase in the S-Cr levels after steroid reduction and withdrawal was 2-4 months in all patients. In all patients, the clinical symptom of steroid withdrawal syndrome was arthralgia, which resolved after restarting steroid administration.

Relationship between $\mathrm{IC}_{50}$ Values of Administered Steroids and CNIs and Clinical Outcome after Steroid Reduction and Withdrawal The number of patients in whom the S-Cr levels increased, who experienced steroid withdrawal syndrome, and for whom the steroid dose was increased or steroid administration restarted was not significantly different between patients normally sensitive and hyposensitive to methylprednisolone (Table 4). We could not statistically analyze the number of patients administered prednisolone because of an insufficient number of cases $(n=5)$. Further, we could not determine whether lymphocyte sensitivity to CYA and TAC was related to clinical outcome, because all of the patients administered CYA $(n=20)$ or those administered TAC $(n=10)$ were normally sensitive to CYA or TAC, respectively.

Comparison of the Lymphocyte Proliferation Rate for Each Concentration of Serum Cortisol between Incident and Non-incident Groups We compared the lymphocyte proliferation rate for each concentration of serum cortisol in
Table 4. Comparison of the Incidence of Events after Steroid Reduction and Withdrawal between Patients Normally Sensitive (NS) and Hyposensitive (HS) to Methylprednisolone

\begin{tabular}{cccc}
\hline \hline & $\begin{array}{c}\text { No. of patients in whom the event occurred/ } \\
\text { No. of patients in whom it did not occur }\end{array}$ \\
\cline { 2 - 4 } $\begin{array}{c}\text { Lymphocyte sensitivity to } \\
\text { methylprednisolone } \\
\left(\mathrm{IC}_{50,}, \mathrm{ng} / \mathrm{ml}\right)\end{array}$ & $\begin{array}{c}\text { Increase in } \\
\text { S-Cr level }\end{array}$ & $\begin{array}{c}\text { Steroid } \\
\text { withdrawal } \\
\text { syndrome }\end{array}$ & $\begin{array}{c}\text { Increase in } \\
\text { dose/restart } \\
\text { of therapy }\end{array}$ \\
\hline $\begin{array}{l}\text { NS group }(<120)(n=17) \\
\text { HS group }(\geqq 120)(n=8)\end{array}$ & 3 & 3 & 4 \\
\hline & N.S & N.S & N.S
\end{tabular}

Fisher's exact probability test.

each patient between the incident and non-incident groups (Fig. 2). Though the lymphocyte proliferation rates were not significant differences in patients in whom the $\mathrm{S}-\mathrm{Cr}$ levels increased $(99.1 \pm 32.6 \%$ vs. $64.4 \pm 33.2 \%)$, in patients who experienced steroid withdrawal syndrome $(86.0 \pm 25.1 \%$ vs. $63.9 \pm 36.3 \%$ ), and in patients in whom the steroid dose was increased or steroid administration was restarted (93.6 \pm $32.0 \%$ vs. $64.3 \pm 33.9 \%$ ) between the incident and non-incident groups, the patients in whom the lymphocyte proliferation rate was less than $60 \%$ did not show increase in $\mathrm{S}-\mathrm{Cr}$ levels, experience steroid withdrawal symptoms, or require an increase in the steroid dose or restart of steroid administration.

Comparison of the Lymphocyte Proliferation Rate for Each Concentration of Serum Cortisol between Normally Sensitive and Hyposensitive Groups The average cortisol concentration-lymphocyte proliferation rate curves for the normally sensitive and hyposensitive groups, and the normal range of serum cortisol concentration (shadow area) are shown in Fig. 3.

With the lower normal limit of serum cortisol, the average lymphocyte proliferation rates were $65.1 \%$ for the normally sensitive group and $101.0 \%$ for the hyposensitive group. The difference in the lymphocyte proliferation rates was $36.0 \%$ 


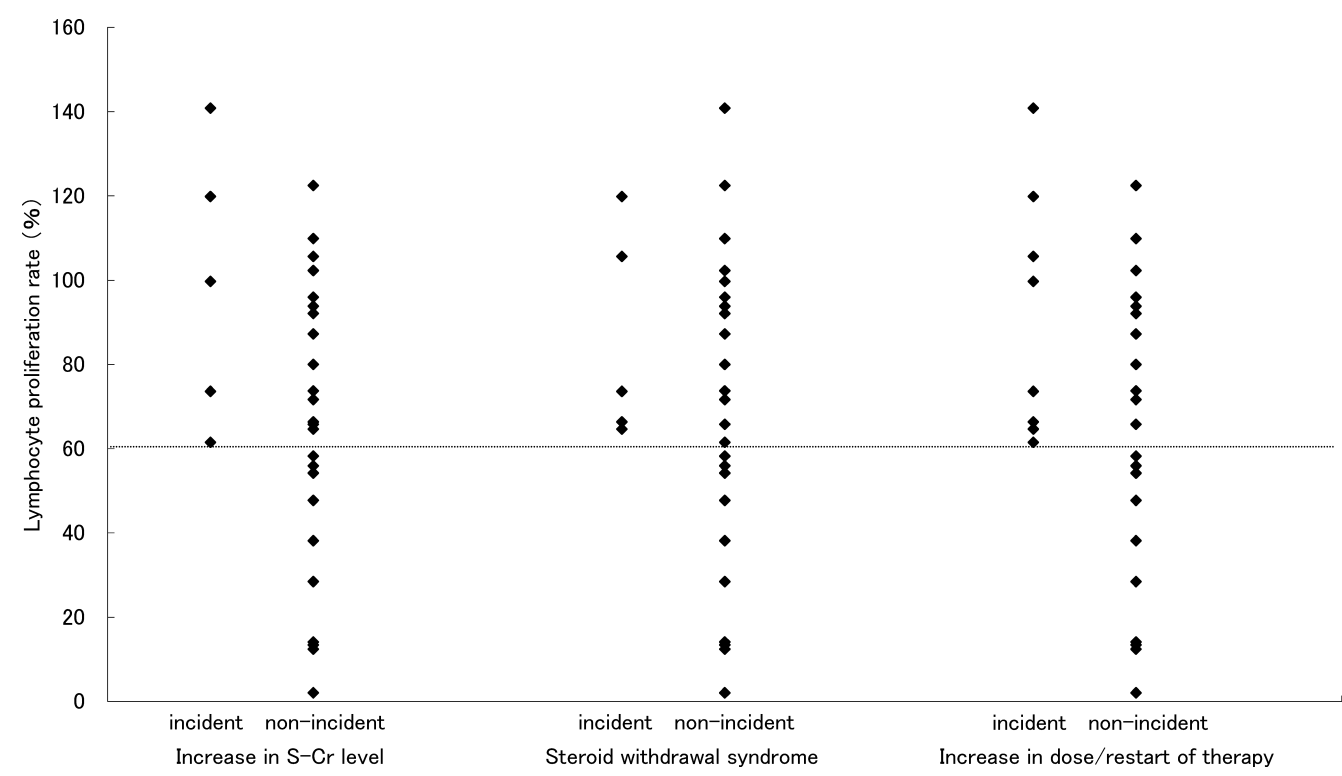

Fig. 2. Comparison of Lymphocyte Proliferation Rate for Each Serum Cortisol Concentration between the Incident and Non-incident Groups after Steroid Reduction/Withdrawal

The incident group included patients in whom the S-Cr or BUN levels increased, who experienced steroid withdrawal syndrome, or for whom the steroid dose was increased or steroid administration restarted and non-incident group included patients who did not fall into either of these categories.

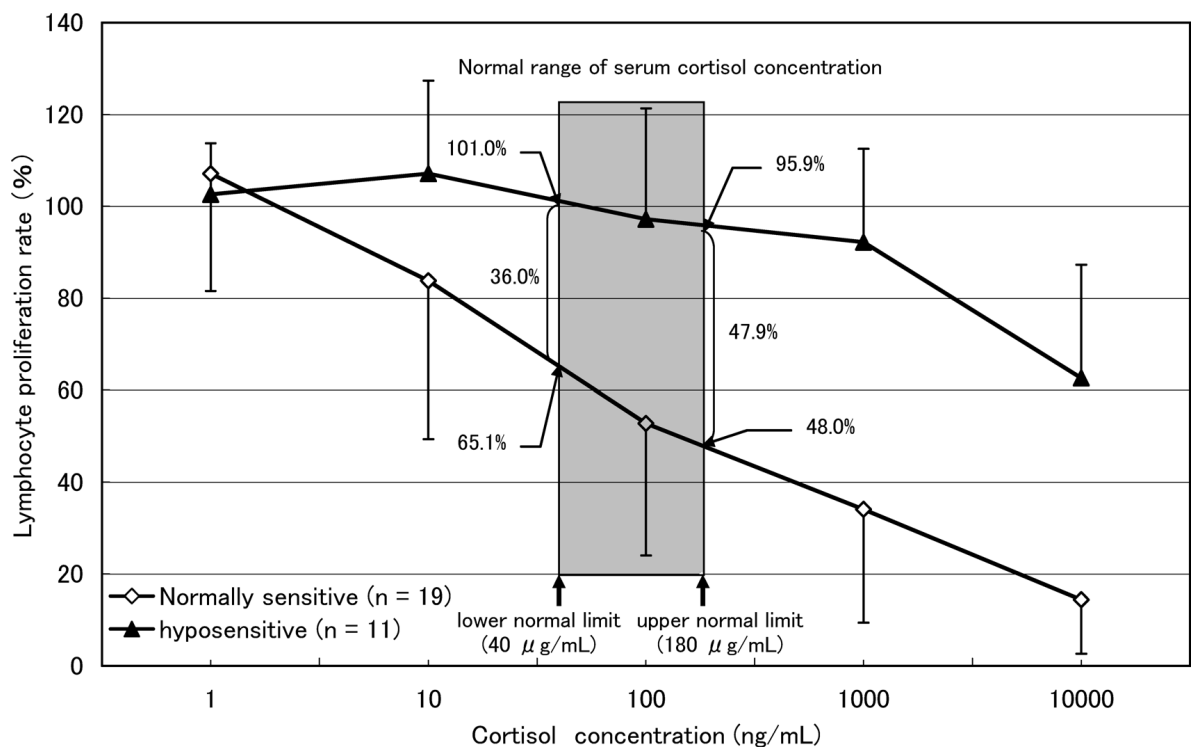

Fig. 3. Comparison of the Average Cortisol Concentration-Lymphocyte Proliferation Rate Curves and the Normal Range of Serum Cortisol Concentration between the Normally Sensitive $(n=19)$ and Hyposensitive Groups $(n=11)$

between the normally sensitive and hyposensitive groups. With the upper normal limit, the average lymphocyte proliferation rates were $48.0 \%$ for the normally sensitive group and $95.9 \%$ for the hyposensitive group, and the difference in lymphocyte proliferation rates between these groups was $47.9 \%$. Furthermore, the averages of lymphocyte prolifera-

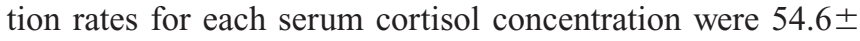
$31.3 \%$ for the normally sensitive group and $97.0 \pm 23.4 \%$ for the hyposensitive group $(p<0.001)$.

\section{DISCUSSION}

Steroid withdrawal after renal transplantation has been attempted in recent times. Steroid withdrawal poses no prob- lems to some patients. However, in some patients, it is necessary to restart steroid administration in order to maintain renal function and prevent acute rejection. ${ }^{6-9)}$ In the Cochrane review, Pascual et al. reported that although steroid avoidance and steroid withdrawal strategies after kidney transplantation were not associated with increased mortality or graft loss, they did increase acute rejection. ${ }^{5)}$ Even now, steroid withdrawal does not have a satisfactory outcome after renal transplantation. ${ }^{6-9,12-14)}$ Currently, there are no indicators to predict which patients can withdraw steroid safely. Only one study has investigated steroid withdrawal based on pharmacodynamic methods and suggested that the number of donor-specific cytotoxic $\mathrm{T}$ lymphocytes increases in the presence of prednisolone in patients who experience acute rejec- 
tion after steroid withdrawal. ${ }^{15)}$

We have demonstrated that the lymphocyte sensitivity, as assessed by the $\mathrm{IC}_{50}$ value, to prednisolone or CYA is significantly associated with the clinical outcomes of acute rejection $^{10)}$ or graft survival. ${ }^{11)}$ The accuracy and repeatability of this assay have been evaluated to be clinically applicable, as we reported previously (ref. 10). Consequently, we assessed lymphocyte sensitivity to endogenous cortisol as a biomarker of steroid withdrawal. We hypothesized that, as the patients hyposensitive to cortisol could not be sufficiently immunosuppressed by their intrinsic cortisol as a immunosuppressive substitute for the reduced or withdrawn steroid, cortisol-hyposensitive patients could not withdraw steroid safety. We found that a significantly higher number of cortisol-hyposensitive patients experienced an increase in S-Cr levels, withdrawal syndrome, and required an increase in the steroid dose or restart of steroid administration. We considered from these observations that investigating the lymphocyte sensitivity to cortisol before reducing and withdrawing steroids might be useful to predict the safety of steroid withdrawal.

The lymphocyte proliferation rates were higher in the incident group than the non-incident group. Within the normal range of serum cortisol concentration, these rates differed by $36.0-47.9 \%$ between patients normally sensitive and hyposensitive to cortisol. These results suggest that $\mathrm{S}-\mathrm{Cr}$ increased because the immunosuppressive efficacy was insufficient in hyposensitive patients. It is unclear why steroid withdrawal syndrome was experienced by a significantly higher number of cortisol-hyposensitive patients; from a cortisol pharmacokinetic point of view, it was considered that steroid withdrawal syndrome is caused by absolute or relative absence of cortisol in the target tissue of the steroid. However, it could be regarded that there would be sufficient amount of cortisol in the articular target tissue, for cortisol concentrations were in a normal range in all patients with arthralgia. From a cortisol pharmadynamic point of view, cortisol sensitivity in the target tissue is possibly influence steroid withdrawal syndrome. The cortisol hyposensitive patients may require higher amount of steroid to prevent the onset of arthralgia than the normally sensitive patients.

In pharmacodynamic/pharmacokinetic data as shown in Fig. 2, patients in whom the lymphocyte proliferation rate for each concentration of serum cortisol in each patient was less than $60 \%$ did not show an increase in S-Cr levels, experience steroid withdrawal symptoms, or required an increase in the steroid dose or restart of steroid administration. This indicates that if the lymphocyte proliferation rate is less than $60 \%$, the patient might be able to withstand steroid reduction and withdrawal. Even the $\mathrm{IC}_{50}$ values (pharmacodynamic data shown in Table 2) taken alone might be useful biomarkers to select patients in whom steroids can be withdrawn.

We hypothesized that the patients with high lymphocyte sensitivity to administered steroids would be easy to reduce to the lower steroid dose to decrease in the threshold level of steroid efficacy. However, lymphocyte sensitivity to administered steroid (methylprednisolone) was not significantly associated with the clinical outcome after steroid reduction. This may be because the individual difference in the $\mathrm{IC}_{50}$ value of methylprednisolone $(0.74-1442.70 \mathrm{ng} / \mathrm{ml})$ was smaller than that in the $\mathrm{IC}_{50}$ of cortisol $(2-10000 \mathrm{ng} / \mathrm{ml})$.

As this study was performed retrospectively, prospective investigation for the relationship between lymphocyte sensitivity to cortisol and clinical outcome in early steroid withdrawal patients, from 2 weeks to 2 months after transplant operation, would be the next issue.

We found that the lymphocyte sensitivity to cortisol could be a important pharmacodynamic factor for steroid withdrawal in renal transplant recipients undergoing long term steroid therapy. Our data also suggested that the lymphocyte sensitivity to endogenous cortisol may be in the normal range if steroids are to be withdrawn more safely because cortisol acts as a substitute for the reduced and withdrawn steroid. Thus, we considered from these observations that the lymphocyte sensitivity to cortisol would be useful for selecting patients for whom steroids should be withdrawn, and as a biomarker to safely reduce and withdraw steroids.

Acknowledgements This study was supported by Grant No. 20590159 from Grant-in-Aid for Scientific Research C and a Grant from the Japan Research Foundation for Clinical Pharmacology. We thank Miss K. Katsuyama for her technical assistance.

\section{REFERENCES}

1) Nashan B., Moore R., Amlot P., Schmidt A. G., Abeywickrama K., Soulillou J. P., Lancet, 350, 1193-1198 (1997).

2) Kahan B. D., Rajagopalan P. R., Hall M., Transplantation, 67, 276284 (1999).

3) Rike A. H., Mogilishetty G., Alloway R. R., Succop P., Roy-Chaudhury P., Cardi M., Kaiser T. E., Thomas M., Woodle E. S., Clin. Transplant., 22, 229-235 (2008).

4) Gallagher M., Jardine M., Perkovic V., Cass A., McDonald S., Petrie J., Eris J., Transplantation, 87, 1877-1883 (2009).

5) Pascual J., Zamora J., Galeano C., Royuela A., Quereda C., Cochrane Database Syst. Rev., 1, CD005632 (2009).

6) Vincenti F., Schena F. P., Paraskevas S., Hauser I. A., Walker R. G., Grinyo J., Am. J. Transplant., 8, 307-316 (2008).

7) Woodle E. S., First M. R., Pirsch J., Shihab F., Gaber A. O., Van Veldhuisen P., Ann. Surg., 248, 564-577 (2008).

8) Kato Y., Tojimbara T., Iwadoh K., Koyama I., Nanmoku K., Kai K., Sannomiya A., Nakajima I., Fuchinoue S., Teraoka S., Int. Immunopharmacol., 6, $1984-1992$ (2006).

9) Tan J. Y., Zhao N., Wu T. X., Yang K. H., Zhang J. D., Tian J. H., Liu Y. L., Wang K. J., Chen F., Li S. F., Li Y. P., Transplant. Proc., 38, 2054 2056 (2006).

10) Hirano T., Oka K., Takeuchi H., Sakurai E., Matsuno N., Tamaki T., Kozaki M., Transplantation, 57, 1341-1348 (1994).

11) Takeuchi H., Hirano T., Oka K., Mizumoto K., Akashi T., Sakurai E., Degawa T., Uchiyama M., Kozaki K., Matsuno N., Nagao T., Kozaki M., Transplant. Proc., 30, 36-39 (1998).

12) Augustine J. J., Hricik D. E., Clin. J. Am. Soc. Nephrol., 1, 1080-1089 (2006).

13) Kasiske B. L., Chakkera H. A., Louis T. A., Ma J. Z., J. Am. Soc. Nephrol., 11, 1910-1917 (2000).

14) Pascual J., Quereda C., Zamora J., Hernández D., Transplantation, 78, 1548 - 1556 (2004)

15) Bouma G. J., Hollander D. A., van der Meer-Prins E. M., van Bree S. P., van Rood J. J., van der Woude F. J., Claas F. H., Transplantation, 62, $1422-1429$ (1996). 